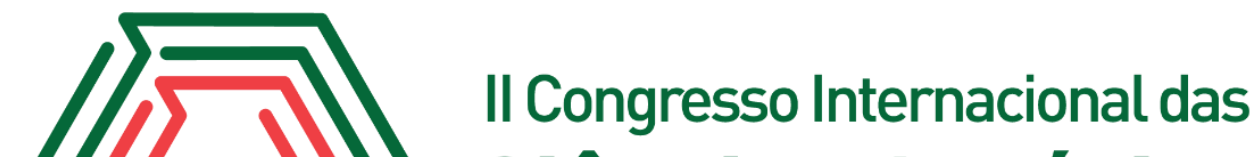 Ciências Agrárias COINTER - PDVAgro 2017
}

\section{EFEITO ALELOPÁTICO DE EXTRATO DE VINAGREIRA (Hibiscus sabdariffa) NA GERMINAÇÃO DE SEMENTES DE QUIABO (ABELMOSCHUS ESCULENTUS)}

\author{
Apresentação: Pôster
}

\begin{abstract}
Jonathan dos Santos Viana ${ }^{1}$; Keyse Cristina Mendes Lopes ${ }^{2}$; Raquel da Silva Lima ${ }^{3}$; Josilda Junqueira $^{4}$
\end{abstract}

\section{Introdução}

O quiabo valência é tido como uma cultura de grande importância econômica na ilha de São Luís, isso devido sua alta exploração no cinturão verde da cidade, favorecendo assim um maior incremento na renda familiar dos pequenos agricultores.

A literatura é deficiente de informações sobre trabalhos envolvendo o efeito de extratos de hortaliça folhosa não convencional na germinação de sementes de quiabo, portanto o estudo de meios que favorecem uma boa germinação desta cultura se faz cada vez mais necessário.

Hoje o agricultor familiar visa não somente a produção para consumo próprio e da família, como também visa à competitividade, e para que o mesmo possa se sobressair em relação à concorrência ele deve se atrelar a meios não muitos caros, mas de fácil acesso que garantam esse sucesso no mercado ao qual ele está inserido.

Visando essa temática o presente trabalho teve como propósito avaliar os extratos de plantas medicinal, aromática e hortaliça não convencional na germinação de sementes de quiabo (Abelmoscus esculentus L) variedade valência.

\section{Fundamentação Teórica}

A alelopatia é definida como o efeito prejudicial ou benéfico entre plantas, por meio de interações químicas, incluindo microorganismos. Os compostos químicos que possuem atividade

\footnotetext{
${ }^{1}$ Agronomia, Universidade Estadual do Maranhão-UEMA, Email: jonathan_santu@hotmail.com

${ }^{2}$ Agronomia, Universidade Estadual do Maranhão-UEMA, E-mail: keisy.agro223@gmail.com

${ }^{3}$ Mestranda em Ciência animal e Pastagem, Universidade Federal Rural de Pernambuco-UFRPE, Email: raquel_lek@hotmail.com

${ }^{4}$ Profa. Dra. Departamento de Fitotecnia e Fitossanidade - DFF, Universidade Estadual do Maranhão-UEMA, E-mail: josilda.ayres@gmail.com
} 
alelopática são resultantes do metabolismo secundário produzido pelas plantas, chamados de aleloquímicos, substâncias alelopáticas ou fitotoxinas. Estas substâncias estão presentes em todos os tecidos das plantas, (folhas, flores, frutos, raízes, rizomas, caules e sementes), mas a quantidade e a via pelas quais são emitidas diferem entre as espécies. O modo de ação dos aleloquímicos pode ser dividido em ação direta e indireta, dependendo da espécie, afetando desde a germinação das sementes até o desenvolvimento da plântula, tornando assim inviável o desenvolvimento da espécie intolerante a estes produtos (VILELA, 2009).

Segundo Guerra (1995) estas substâncias químicas conhecidas por compostos alelopáticos são substâncias tóxicas liberadas no meio ambiente por meio de volatilização, decomposição da matéria orgânica ou por lixiviação de partes de plantas. Muitos destes compostos podem ser eliminados rapidamente e outros podem permanecer no solo por períodos longos, comprometendo o processo de decomposição da matéria orgânica, produção de húmus, mineralização de nutrientes e o uso do solo para cultivos agrícolas posteriores.

A atividade dos aleloquímicos tem sido usada como alternativa ao uso de herbicidas, inseticidas e nematicidas (defensivos agrícolas). A maioria destas substâncias provém do metabolismo secundário, porque na evolução das plantas representaram alguma vantagem contra a ação de microrganismos, vírus, insetos, e outros patógenos ou predadores, seja inibindo a ação destes ou estimulando o crescimento ou desenvolvimento das plantas (WALLER; FEUG; FUJII, 1999).

\section{Metodologia}

O experimento foi realizado no Laboratório de Análise de Sementes, do Centro de Ciências Agrárias da Universidade Estadual do Maranhão localizada na Cidade Universitária Paulo VI - Campus São Luís/MA no período de Novembro de 2016 a Janeiro de 2017.

\section{Material vegetal}

Foram utilizadas folhas de hortaliça folhosa não convencional (vinagreira) que foram adquiridas em feiras e mercados por meio de compra. As sementes da espécie de planta de quiabo que apresenta um valor econômico e agronômico foram adquiridas em casas agropecuárias no mês de outubro de 2016.

\section{Preparo do extrato vegetal}


Foram preparados extratos aquosos das folhas secas da hortaliça folhosa não convencional (vinagreira) de acordo com a metodologia proposta por Santore (2013).

\section{Teste de germinação}

Para o teste de germinação, foram utilizadas quatro repetições de 25 sementes de quiabo valência distribuídas em rolo de papel germitest (RP) de acordo com as recomendações RAS Regras para Análises de Sementes (BRASIL, 2009) e após 3 dias foi avaliada a percentagem de germinação das sementes. Foi utilizado o recomendado por Laboriau e Valadores (1976, apud NETO, 2010), no qual a germinação foi determinada pela formula $\mathrm{G}=\mathrm{N} / \mathrm{A} \times 100$. Onde $\mathrm{N}-$ número de sementes germinadas e $\mathrm{A}$ - número total de sementes colocadas para germinar.

\section{Teste de Índice de Velocidade de Germinação (IVG)}

O IVG foi obtido em conjunto com o teste de germinação de acordo com fórmula proposta por Maguire (1962): IVG $=[\mathrm{N} 1 / 1+\mathrm{N} 2 / 2+\mathrm{N} 3 / 3+\ldots+\mathrm{Nn} / \mathrm{n}]$ x 100, onde: N1, N2, N3 e Nn correspondem à proporção de sementes germinadas no primeiro, segundo, terceiro e enésimo dia a partir da semeadura.

\section{Massa seca de plântulas}

Para obtenção de massa seca total todas as plântulas normais de cada tratamento e repetição foram acondicionadas em sacos de papel do tipo kraft e transferida para estufa com circulação de ar forçado, regulada para $65^{\circ} \mathrm{C}$ até atingirem peso constante (24h), em seguida o material foi pesado em balança analítica de precisão $(0,001 \mathrm{~g})$ e os resultados foram expressos em $\mathrm{g}$ plântula $^{-1}$ (CARVALHO; NAKAGAWA, 1999)

\section{Teste de comprimento de raiz}

Para determinação do comprimento de raiz das plântulas estas foram retiradas cuidadosamente do substrato, e medidas com auxílio de régua graduada em centímetros e os resultados foram expressos em cm plântula ${ }^{-1 .}$ (CARVALHO; NAKAGAWA, 1999).

\section{Delineamento experimental e análise estatística}

O delineamento experimental adotado foi o inteiramente casualizado (DIC), utilizandose o extratos de vinagreira com 5 concentrações (tratamentos) e 4 repetições . Os resultados obtidos foram submetidos à análise de variância e os efeitos de tratamentos (concentrações) que 
apresentaram diferença significativa $(\mathrm{P}<0,01)$, as médias foram comparadas por meio da aplicação do Teste de Tukey a 5\% de probabilidade.

\section{Resultados e Discussões}

Percebeu-se que a literatura não registra dados quanto ao uso de extratos de vinagreira com vistas ao possível efeito alelopático sobre a germinação de sementes de quiabo valência. A germinação variou entre $47 \%$ a $70 \%$ nos extratos de vinagreira a 5\%, 10\%, 15\% e $20 \%$ não apresentando diferença em relação à concentração $0 \%$ (testemunha).

TABELA 1 - Porcentagem de germinação ao $7^{\circ}$ dia após semeadura, índice de velocidade de germinação (IVG), comprimento de raiz $(\mathrm{cm})$, parte aérea $(\mathrm{cm})$ e matéria seca $(\mathrm{g})$ de plântula de sementes de quiabo (Abelmoscus esculentus) variedade Valência sob efeito de extrato de vinagreira (Hibiscus sabdariffa).

\begin{tabular}{|c|c|c|c|c|c|}
\hline $\begin{array}{l}\text { Doses do } \\
\text { extrato }(\%)\end{array}$ & Germinação (\%) & IVG (\%) & $\begin{array}{l}\text { Comprimento de } \\
\text { raiz }(\mathrm{cm})\end{array}$ & $\begin{array}{l}\text { Parte aérea } \\
(\mathrm{cm})\end{array}$ & $\begin{array}{l}\text { Matéria seca } \\
\text { (g plântula }^{-1} \text { ) }\end{array}$ \\
\hline 0 & $70 \mathrm{a}$ & $16,93 \mathrm{a}$ & $4,41 \mathrm{a}$ & $7,09 \mathrm{a}$ & $0,012 \mathrm{ab}$ \\
\hline 5 & $55 \mathrm{a}$ & $11,91 \mathrm{a}$ & $0,00 \mathrm{~d}$ & $0,00 \mathrm{~b}$ & $0,000 \mathrm{~b}$ \\
\hline 10 & $47 \mathrm{a}$ & $10,59 \mathrm{a}$ & $1,01 \mathrm{c}$ & $5,09 \mathrm{a}$ & $0,122 \mathrm{ab}$ \\
\hline 15 & $56 \mathrm{a}$ & $12,14 \mathrm{a}$ & $2,08 \mathrm{~b}$ & $7,52 \mathrm{a}$ & $0,185 \mathrm{a}$ \\
\hline 20 & $56 \mathrm{a}$ & $10,64 \mathrm{a}$ & $0,35 \mathrm{~cd}$ & $2,08 \mathrm{~b}$ & $0,054 \mathrm{~b}$ \\
\hline CV \% & 26 & 24 & 28 & 30 & 58 \\
\hline
\end{tabular}

Médias seguidas de mesma letra nas colunas, não diferem entre si pelo Teste de Tukey, ao nível de 5\% de probabilidade.

Apesar de não ocorrer tal diferença entre as concentrações, o extrato de vinagreira apresentou-se efêmero no que diz respeito à germinação, pois poucas sementes germinaram, além do mais, mesmo apresentando uma alta acidez isso não impediu a ocorrência de fungos durante a germinação. A vinagreira em sua composição apresenta o ácido cítrico que é considerado um aleloquímico, essa concentração pode ter influenciado diretamente na divisão celular de algumas sementes ocasionando suas mortes.

Em nenhuma das concentrações estudadas interferiu no índice de germinação das sementes de quiabo valência, isso relata o fato de que todas as sementes expostas a esse extrato germinaram praticamente no mesmo tempo, mas a testemunha $(0 \%)$ levando-se em consideração quanto maior o IVG maior o vigor, foi a que mais se destacou. 
O comprimento de raiz $(\mathrm{cm})$ de acordo com a Tabela 1, na concentração $0 \%$ do extrato de vinagreira (testemunha) apresentou-se maior seguida da concentração a $15 \%$. Apesar de ser considerada uma planta com elevados teores de vitamina $\mathrm{C}$ a atividade de microrganismos patogênicos não foi sessada, resultando em um pior valor para a concentração de $5 \%$ do extrato desta hortaliça não convencional tanto para comprimento de raiz quanto para comprimento de plântulas de quiabo valência.

Em relação à matéria seca de plântulas de quiabo valência, as concentrações de $0 \%$, $10 \%$ e $15 \%$ apresentaram melhores resultados. Nesse caso ocorreu uma maior absorção de extrato pela semente no momento do processo de embebição, resultando nesse melhor desempenho em termo de peso seco (variando entre 0,012 a 0,185 g de plântulas).

\section{Conclusões}

O extrato de vinagreira, apesar de ter favorecido a germinação não é indicada para uso em germinação de sementes de quiabo valência, pois possui alelopatia oriunda de suas folhas que causa morte de sementes além de favorecer, mesmo tendo em sua composição o ácido cítrico, o aparecimento de fungos patogênicos que deterioram as sementes.

\section{Referências}

CARVALHO, N.M.; NAKAGAWA, J. Sementes: ciência tecnologia e produção. Jaboticabal: FUNEP, 2012. 590p.

GUERRA, C. B.(Coordenador) Meio ambiente e trabalho no mundo do eucalipto. 2 ed. Editora Associação Agência Terra, 1995. 143 p.LIMA, W. P. Impacto ambiental de eucalipto. 2 ed. São Paulo: Editora Edusp, 1996. 301 p.

MAGUIRE, J.D. Speed of germination-aid selection and evaluation for seedling emergence and vigor. Crop Science, v.2, n.2, p.176-177, 1962.

NETO, E. N. A. Potencial alelopático de leucena e de sabiá na germinação, na emergência e no crescimento inicial de sorgo. 2010. 29 f. Monografia apresentada á Universidade Federal de Campina Grande para obtenção do grau de Engenheiro Florestal. Universidade Federal de Campina Grande Campus Patos. Pernambuco. 2010.

SANTORE, S.. Atividade alelopática de extratos de plantas medicinais na germinação de corda de viola. 2013. 56f. Monografia apresentada ao curso de Tecnologia em Biotecnologia. Universidade Estadual do Paraná, Palotina. 2013.

VILELA, Herbert. Agronomia: o portal da ciência e tecnologia. Disponivel em: <http:// http://www.agronomia.com.br/conteudo/artigos/artigos_alelopatia_e_os_agrossistemas.html>.

Acesso em: 05 de out.2016 